Buse Güler*, Dilek Bilgiç, Hülya Okumuş, Hande Yağcan and Murat Alan

\title{
An investigation of vitamin and mineral supplement recommendation among first-trimester pregnancies
}

https://doi.org/10.1515/jpm-2019-0178

Received April 26, 2019; accepted September 17, 2019; previously published online October 17, 2019

\begin{abstract}
Background: Healthy and balanced nutrition in pregnancy can affect the mother's and the fetus' health. Therefore, health professionals should provide information about this issue to pregnant women. The aim of the study was to examine the rate of vitamin and mineral supplement recommendation among first-trimester pregnant women.

Methods: The study sample consisted of 697 first-trimester pregnant women between 18 and 40 years of age. The pregnant women who registered to an obstetric outpatient clinic between January and June 2018 were retrospectively reviewed, and data were collected from patient medical records using a questionnaire.

Results: Physician's laboratory test orders from the women included the following: ferritin was $18.4 \%$, mean corpuscular hemoglobin (MCH) was $99.7 \%$, folic acid was $10.2 \%$, vitamin D was $6.3 \%$, vitamin B12 was $17.2 \%$ and calcium was $20.4 \%$. All of the women's hemoglobin levels had been examined. A total of $58.8 \%$ of the women were recommended to take folic acid, $32.7 \%$ iron, $25.7 \%$ iodine, $18.8 \%$ calcium, $17.2 \%$ vitamin $\mathrm{A}, 21.1 \%$ vitamin $\mathrm{B} 12,17.4 \%$ vitamin C, $31.6 \%$ vitamin D and $17.5 \%$ vitamin E supplements.

Conclusion: It was determined that ferritin, vitamins B12 and $\mathrm{D}$, calcium, folic acid, iron and iodine levels were not examined routinely in this study. Folic acid and iron supplementation were the most commonly suggested nutrient supplements in the first trimester.
\end{abstract}

Keywords: nutrient supplement; pregnancy; vitamins.

*Corresponding author: Buse Güler, PhD Candidate, Research Assistant, Department of Gynecology and Obstetric Nursing, Dokuz Eylul University, Faculty of Nursing, Institute of Health Sciences, Balçova, İzmir 35340, Turkey, Tel.: +90 554501 6560, Fax: +90 232 412 4798, E-mail: busebahitli@gmail.com

Dilek Bilgiç, Hülya Okumuş and Hande Yağcan: Department of Gynecology and Obstetric Nursing, Dokuz Eylul University, Faculty of Nursing, Balçova, İzmir, Turkey

Murat Alan: Sağlık Bilimleri University, Tepecik Education and Research Hospital, Konak, İzmir, Turkey

\section{Introduction}

The nutrients taken during pregnancy affect the health of the fetus and the pregnant woman as well as the health of the mother and the newborn in the postpartum period. Because of the mother's physiological changes and the development of the fetus, there is an increase in nutrient requirements in pregnancy. Thus, an adequate and balanced diet becomes important [1]. Although weight gain and energy intake are important in pregnancy, several factors including age, physical activity and pre-pregnancy body weight influence nutrition requirements during pregnancy [2]. The requirement for vitamins and minerals increase by $20-100 \%$ in pregnancy [3, 4]. Some pregnant women require nutrient supplementation for some different reasons.

In order to protect the health of the mother and the newborn, it is recommended to evaluate all women at fertility age for malnutrition and to provide multivitamin supplementation in doubtful situations [5]. In cases where an adequate and balanced diet cannot be achieved in pregnancy, nutrient supplementation may reduce the risk of various pregnancy complications such as preeclampsia, gestational diabetes and intrauterine growth deficiency, and will contribute to the baby's health throughout his or her life [1, 2].

The World Health Organization (WHO), Royal College of Obstetricians and Gynecologists (RCOG), National Institute for Health and Care Excellence (NICE), American College of Obstetricians and Gynecologists (ACOG), American Institute of Medicine (IOM) and The Republic of Turkey Ministry of Health (TR MoH) give different suggestions on nutrition support during pre-pregnancy and pregnancy [6-10]. The WHO [6] recommends daily iron and folic acid supplementation in pregnant women at a dose of 30-60 mg of elemental iron, while TR MoH [11] recommends an iron supplementation of 40-60 mg daily starting in the fourth month of the pregnancy. The WHO [6] and the Food and Agriculture Organization of the United Nations (FAO) recommend a calcium intake of $1200 \mathrm{mg} /$ day for pregnant women from the $20^{\text {th }}$ week of pregnancy to delivery. In addition, the WHO [6] recommends daily calcium 
supplementation (1.5-2.0 g oral original calcium) to reduce the risk of preeclampsia in pregnant women with low dietary calcium intake. The NICE [8] states that supplementation with vitamin A (intake above $700 \mu \mathrm{g}$ ) might be teratogenic in pregnant women. There is no recommendation on vitamin A supplementation in pregnancy in the Prenatal Care Management Guideline of TR MoH [12]. The WHO [13] recommends dietary intake of vitamin B12 and nutritional supplementation where necessary. The ideal amount of supplemental vitamin B12 is less clear. The recommended daily intake is $2.6 \mu \mathrm{g} /$ day [14]. The WHO [6] does not recommend vitamin $C$ supplementation to improve maternal and perinatal outcomes of pregnant women. The promotion of adequate vitamin $\mathrm{C}$ by pregnant women with a healthy and balanced diet is recommended because it is easy to consume sufficient amounts of vitamin C from food sources. The RCOG [7] suggests a multivitamin with low doses of vitamins $\mathrm{C}$ and $\mathrm{E}$ during pregnancy. For vitamin D supplementation, the ACOG [9] recommends routine supplementation during pregnancy, while the IOM recommends $600 \mathrm{IU} /$ day intake and the WHO [6] does not recommend for pregnant women.

Several factors in pregnant women, such as socioeconomic status, awareness and receiving antenatal care, affect nutritional supplement intake [15, 16]. Health professionals should also provide information about this issue to pregnant women. This study is very important to find out the similarities and differences between the guideline recommendations of the health organizations in the world and the current recommendations and implications in the state hospital of our country. Therefore, this pilot study was planned with the aim of retrospectively examining the status of receiving of vitamin and mineral supplements among first-trimester pregnant women.

\section{Materials and methods}

This was a retrospective and descriptive type of study, and the data were collected in June 2018 by reviewing the medical records of pregnant women in one of the main research hospitals of the province of Izmir. The study sample consisted of 697 (all) first-trimester pregnant women between 18 and 40 years of age who registered to an obstetric outpatient clinic of the hospital between January and June 2018. The exclusion criteria of this study were pregnant women who were in their second or third trimesters or had a chronic illness prior to their pregnancies.

The data were collected from patient records using a questionnaire which was composed by the researchers. This questionnaire form included questions about age, gravida, parity, number of abortions and body mass index (BMI). The form evaluated whether health care providers had ordered laboratory tests measuring hemoglobin, ferritin, mean corpuscular hemoglobin (MCH), folic acid, vitamin
B12, vitamin D and calcium levels. The form also evaluated whether women had been recommended to take folic acid; iron; vitamins A, B6, B12, C, D and E; and calcium. For data analysis of the independent variables, descriptive statistics and IBM SPSS Statistics 22 program (IBM Corp., Armonk, NY, USA) were used. The required permissions from the Research Hospital Ethical Committee (24/05/2018, No: 2018/5-2) were received.

\section{Results}

The average age of the pregnant women was $27.7 \pm 6.12$ years, number of pregnancies was $2.25 \pm 1.19$ and weight was $67.95 \pm 8.46 \mathrm{~kg}$ (Table 1 ).

According to patient medical records, physician's laboratory test orders from the women included the following: ferritin was $18.4 \%$, MCH was $99.7 \%$, folic acid was $10.2 \%$, vitamin D was $6.3 \%$, vitamin B12 was $17.2 \%$ and calcium was $20.4 \%$. The hemoglobin levels of all the women had been examined (Table 2).

According to the patient medical records, $58.8 \%$ of the pregnant women were recommended to take folic acid and $32.7 \%$ iron. It was found that more than half of the pregnant women $(68.4 \%)$ were not suggested to take

Table 1: Characteristics of the pregnant women $(n=697)$.

\begin{tabular}{lrrr}
\hline & Min & Max & $\overline{\boldsymbol{X}} \pm \mathbf{S D}^{\mathbf{a}}$ \\
\hline Age & 15 & 40 & $27.77 \pm 6.12$ \\
Gravida & 1 & 7 & $2.25 \pm 1.19$ \\
Parity & 0 & 4 & $1.02 \pm 0.93$ \\
Abortions & 0 & 3 & $0.23 \pm 0.58$ \\
BMI & 18.37 & 34.89 & $26.25 \pm 2.87$ \\
\hline
\end{tabular}

aStandard deviation.

Table 2: Ordered laboratory tests and nutrient supplementation recommendations $(n=697)$.

\begin{tabular}{|c|c|c|}
\hline & $\begin{array}{r}\text { Rate of ordered } \\
\text { labs, \% }(n=697)^{a}\end{array}$ & $\begin{array}{r}\text { Recommended } \\
\text { supplementation, \% }\end{array}$ \\
\hline Hemoglobin & 100.0 & - \\
\hline $\mathrm{MCH}$ & 99.7 & - \\
\hline Ferritin & 18.4 & 32.7 \\
\hline Folic acid & 10.2 & 58.8 \\
\hline Vitamin A & 0 & 17.2 \\
\hline Vitamin B12 & 17.2 & 21.1 \\
\hline Vitamin C & 0 & 17.4 \\
\hline Vitamin D & 6.3 & 31.6 \\
\hline Vitamin E & 0 & 17.5 \\
\hline Calcium & 20.4 & 18.8 \\
\hline
\end{tabular}

${ }^{a}$ More than one lab test was ordered from the pregnant women. 
vitamin $\mathrm{D}$. The majority of the patients were not provided any supplementation with vitamin A (82.8\%), vitamin B12 (78.9\%), vitamin C (82.6\%) or vitamin E (82.5\%) (Table 2).

\section{Discussion}

Prenatal caregivers have the potential to provide nutritional counseling. Obstetricians and nurses experience uncertainty about the most appropriate approach while providing weight gain and nutritional advice for pregnant women. In addition, different recommendations in the guidelines for nutritional supplements and physicians' lack of time for consultation change the practices of health professionals in vitamin and mineral supplementation. Pregnant women who do not get adequate information and counseling are interested in using herbal products and nutritional supplements. The rate of multivitaminmineral supplement in pregnant women is reported to be 40-91\% in the world [17-20].

During pregnancy, hematological and hemostatic changes occur in order to ensure harmony between both the mother and the fetus. Hematological changes that occur are evaluated by parameters such as erythrocyte mass, hemoglobin, hematocrit and ferritin. Although there is an increase in red blood cell production during pregnancy, anemia occurs because of the marked increase in plasma volume. Anemia is a common complication of pregnancy, and it is an important problem both for maternal and infant health. During pregnancy, it may cause several health problems such as neonatal mortality, cesarean delivery, preterm delivery, abortion and low birth weight [21]. TR MoH Pregnancy Follow-up Protocol [12] recommends analyzing ferritin and hemoglobin levels in the $14^{\text {th }}$ week of gestation, if possible; if not, it is recommended that healthcare providers analyze hemoglobin values. In this study, it was found that healthcare providers ordered hemoglobin levels for all of the women and $\mathrm{MCH}$ in $99.7 \%$ of them, while the rate of ordering ferritin was low according to laboratory test results. This indicates that hemoglobin and $\mathrm{MCH}$ values in pregnant women are analyzed to find anemia by healthcare professionals during routine checks. Therefore, low rate of ferritin orders may have been due to the fact that physicians merely check hemoglobin values to have a general idea of the status of pregnant women, and they use ferritin less in practice.

The iron requirement increases in the second and third trimesters of the pregnancy due to the increase in blood volume to meet the fetal and placental needs [22].
One of the factors causing anemia in pregnancy is nutrition-based iron deficiency. In a study conducted by Çitıl et al. [23], iron deficiency anemia was found to be significantly higher in pregnant women who drank dark tea and did not use iron-multivitamin preparations. The WHO [6] recommends 30-60 mg of daily elemental iron supplementation for pregnant women to prevent maternal anemia, puerperal sepsis, low birth weight and preterm birth. Due to maternal and fetal effects of iron deficiency, the "Iron Support Program" was launched by TR MoH in 2007. Although pregnant women may not have any clinical anemia, TR MoH takes into consideration their daily iron requirement and recommends $40-60 \mathrm{mg} /$ day of elemental iron for pregnant women during pregnancy, specifically the 6-month period of time starting in the fourth month (second trimester) of the pregnancy to continue until 3 months after the birth (postpartum period) [11]. According to the study results, recommendations for iron supplementation were given to less than one third of the pregnant women. This may be because the women were only in their first trimester of pregnancy which indicated that in the first trimester of the pregnancy anemia had not started yet. Pregnant women require iron supplementation based on undernutrition.

Folic acid supplementation is suggested in the first trimester of pregnancy and even starting from the preconceptional period without measuring blood levels to prevent neural tube defects. Therefore, it is likely that the folic acid levels of the pregnant women in this study were not checked. Folate is required during pregnancy for the growth and development of the fetus, expansion of the uterus, development of the placenta and an increase in the maternal blood cell volume. It is definitely known that folic acid is a protector against miscarriage risk, preterm birth, low birth weight and fetal growth defects, and it protects the fetus from the risk of neural tube defects [22, 24]. The WHO [6] recommends a daily 400- $\mu \mathrm{g}(0.4 \mathrm{mg})$ folic acid supplement, while TR MoH [2] recommends a 400- $\mu \mathrm{g} /$ day folic acid supplement in the diet starting from the pre-conceptional period and during the first 3 months of the pregnancy to prevent neural tube defects. However, we found that folic acid was recommended to only about half of the pregnant women (58.8\%); so this is insufficient based on the recommendation of TR $\mathrm{MoH}$.

Vitamin A deficiency has long been recognized in much of South and Southeast Asia by the common presentation of clinical cases of xerophthalmia or night blindness, mostly in the latter half of the pregnancies. Vitamin A deficiency during pregnancy can result in fetal wastage, although high doses in early pregnancy can be teratogenic as well [25]. In this study, vitamin A was not studied in any 
pregnant women and vitamin A supplement was recommended to very few pregnant women. Due to the fact that Turkey is not among the regions where have seen vitamin A deficiency, vitamin A levels of pregnant women could not be checked by doctors in this study. Vitamin A supplement is recommended usually in multivitamin supplement drugs in Turkey.

Inadequate vitamin B12 status during pregnancy has consequences for both the mother and the fetus. Vitamin B12 deficiency is associated with an increased risk for early recurrent abortion. The use of serum vitamin B12 concentration alone to assess vitamin B12 status in pregnant women is unreliable because of the decrease in serum vitamin B12 levels in normal pregnancy [26]. In this study, the low rate of vitamin B12 level checking may be associated with lack of accurate results due to decreased vitamin B12 level in pregnancy.

Vitamin $\mathrm{C}$ and $\mathrm{E}$ supplementation may help reduce the risk of pregnancy complications such as preeclampsia, intrauterine growth restriction and maternal anemia. However, there is not enough evidence of vitamin C supplementation during pregnancy [27, 28]. In our study, vitamin $\mathrm{C}$ and $\mathrm{E}$ levels were not ordered in any pregnant women. Vitamins $\mathrm{C}$ and $\mathrm{E}$ in pregnancy are usually given in multivitamin-containing tablets in our country.

If babies who are born to mothers with vitamin D deficiency are not given vitamin D supplementation, their serum 25-hydroxyvitamin D (circulating form and indicator of vitamin D) levels rapidly decrease and cause hypocalcemia and/or a defect in calcification of the cartilage matrix (congenital rickets) in the newborn period [10]. The WHO [6] does not recommend vitamin D for pregnant women to improve their maternal and perinatal results. TR MoH [10] suggests vitamin D supplementation to all pregnant women without checking their blood level starting from 12 weeks of pregnancy until 6 months postpartum and during breastfeeding. In this study, the low rate of vitamin D level checking may be associated with this recommendation. Also, the reason for low rates of vitamin D level ordering is probably that the data were collected from pregnant women in the first trimester of their pregnancy.

Inadequate consumption of calcium by pregnant women may cause maternal and fetal effects, including osteopenia, tremor, paresthesia, muscle cramps, tetanus, late growth, low birth weight and poor fetal mineralization [6]. The absorption of calcium increases during pregnancy, and calcium needs in pregnancy can be met through normal nutrition, without requiring any additional supplementation. However, the WHO recommends calcium intake for pregnant women in societies known for inadequate calcium intake. Similarly, in this study, calcium supplementation was given to the pregnant women who required calcium. As the WHO does not consider our country insufficient in terms of calcium intake, it is possible that the healthcare providers in this study might not have routinely checked calcium levels of the pregnant women.

\section{Conclusion}

In this study, it was observed that only the hemoglobin levels of the pregnant women were assessed during the first trimester while ferritin, vitamins B12 and D, calcium, folic acid, iron and iodine values were not routinely checked. In addition, we determined that folic acid, iron and vitamin D supplements were the most recommended nutrient supplements for pregnant women.

Acknowledgments: The authors are grateful to the women who agreed to participate in this study.

Author contributions: All the authors have accepted responsibility for the entire content of this submitted manuscript and approved submission.

Research funding: None declared.

Employment or leadership: None declared.

Honorarium: None declared.

Competing interests: The funding organization(s) played no role in the study design; in the collection, analysis, and interpretation of data; in the writing of the report; or in the decision to submit the report for publication.

Ethical approval: The required permissions from the research hospital Ethical Committee (24/05/2018, No: 2018/5-2) were received.

\section{References}

1. Koenig MD. Nutrient intake during pregnancy. J Obstet Gynecol Neonat Nurs 2017;46:120-2.

2. Ersoy G, Rakıcıoğlu N, Karabudak E, Gökmen Özel H, Köksal H, Özer $E$, et al. Yaşam sürecinde beslenmenin önemi ve enerji dengesi [The importance of nutrition in the life process and energy balance]. In: Pekcan AG, Şanlıer N, Baş M, editors. Türkiye beslenme rehberi [Turkey nutrition guide]. Ankara, Turkey: T.C. Sağlık Bakanlığı, No: 1031, 2015:102-5 [in Turkish].

3. Coşkun A, Özdemir Ö. Gebelikte vitamin ve mineral kullanımı ve beslenmenin irdelenmesi [Evaluation of nutrition and mineralvitamin use during pregnancy]. Türkiye Jinekoloji ve Obstetri Derneği Dergisi 2009;6:155-70 [in Turkish].

4. Özalper B. Gebelikte beslenme [Nutrition in pregnancy]. Muş Alparslan Üniversitesi Fen Bilimleri Dergisi 2014;2:270-8 [in Turkish].

5. Güler Baysoy N, Özkan S. Gebelik öncesi (prekonsepsiyonel) bakım: halk sağlığı perspektifi [Preconception care: a public health perspective]. Gazi Med J 2012;23:77-90 [in Turkish]. 
6. World Health Organization (WHO). WHO recommendations on antenatal care for a positive pregnancy experience [Internet], 2017. [cited 2017 Nov 25]. Available from: http://www.who.int/ reproductivehealth/publications/maternal_perinatal_health/ anc-positive-pregnancy-experience/en/.

7. Royal College of Obstetricians and Gynecologists (RCOG). Vitamin supplementation could have a significant impact on maternal and fetal health, says new review [Internet], 2012. [cited 2017 Nov 26]. Available from: https://www.rcog.org.uk/ en/news/vitamin-supplementation-could-have-a-significantimpact-on-maternal-and-fetal-health-says-new-review/.

8. NICE. Antenatal care for uncomplicated pregnancies: overview [Internet], 2008. [cited 2018 Nov 26]. Available from: https://pathways.nice.org.uk/pathways/antenatal-care-foruncomplicated-pregnancies\#content=view-node\%3Anodesnutritional-supplements\&path=view\%3A/pathways/ antenatal-care-for-uncomplicated-pregnancies/antenatal-carefor-uncomplicated-pregnancies-lifestyle-considerations.xml.

9. American College of Obstetricians and Gynecologists (ACOG). Vitamin D: screening and supplementation during pregnancy committee opinion [Internet]. 2011:495. [cited 2018 Nov 25]. Available from: https://www.acog.org/ Clinical-Guidance-and-Publications/Committee-Opinions/ Committee-on-Obstetric-Practice/Vitamin-D-Screening-andSupplementation-During-Pregnancy.

10. Republic of Turkey Ministry of Health [TR MoH-Sağlık Bakanlığı]. Gebelere d vitamini destek programı rehberi [Guide to vitamin D supplement for pregnant women] [Internet]. 2012 [in Turkish]. [cited 2018 Nov 23]. Available from: https://www.saglik.gov.tr/ TR,11158/gebelere-d-vitamini-destek-programi.html.

11. Republic of Turkey Ministry of Health [TR MoH-Sağlık Bakanlığı] [Internet]. 2007 [in Turkish]. [cited 2018 Nov 22]. Available from: http://www.saglik.gov.tr/TR,11100/gebelerde-demir-destekprogrami-uygulumasi-genelgesi-2007--6.html.

12. Republic of Turkey Ministry of Health [TR MoH-Sağlık Bakanlığı]. Doğum öncesi bakım yönetim rehberi [Prenatal care management guide]. [Internet]. 2014 [in Turkish]. [cited 2019 Oct 2]. Ankara. Available from: https://sbu.saglik.gov.tr/Ekutuphane/ kitaplar/dogumonubakim.pdf.

13. WHO. Conclusions of a WHO Technical Consultation on folate and vitamin B12 deficiencies. Food Nutr Bull [Internet] 2008;29(2 Suppl). The United Nations University. Available from: https://www.who.int/nutrition/publications/micronutrients/FNBvol29N2supjun08.pdf. [cited 2019 Feb 7].

14. WHO. Preventing and controlling micronutrient deficiencies in populations affected by an emergency [Internet]. 2007. [cited 2019 Feb 7]. Available from: https://www.who.int/nutrition/publications/micronutrients/WHO_WFP_UNICEFstatement.pdf.

15. Bener A, Al Maadid MGA, Al-Bast DA, Al-Marri S. Maternal knowledge, attitude and practice on folic acid intake among Arabian Qatari women. Reprod Toxicol 2006;21:21-5.
16. Rivera-Segarra S, Ramos-Tollinchi L, Cardenas-Suarez N. Knowledge and use of folic acid among Hispanic women visiting university of Puerto Rico prenatal clinics. Obstet Gynecol 2017;129:111.

17. Bercaw J, Maheshwari B, Sangi-Haghpeykar H. The use during pregnancy of prescription, over-the-counter, and alternative medications among Hispanic women. Birth 2010;37:211-8.

18. Bishop JL, Northstone K, Green JR, Thompson EA. The use of complementary and alternative medicine in pregnancy: data from the Avon Longitudinal Study of Parents and Children (ALSPAC). Complement Ther Med 2011;19: 303-10.

19. Frawley J, Adam J, Sibbritt D, Steel A, Broom A, Gallois C. Prevalence and determinants of complementary and alternative medicine use during pregnancy: results from a nationally representative sample of Australian pregnant women. Aust N Z J Obstet Gynaecol 2013;53:347-352.

20. Blumfield ML, Hure AJ, Macdonald-Wicks L, Smith R, Collins CE. Micronutrient intakes during pregnancy in developed countries: systematic review and metaanalysis. Nutr Rev 2013;71:118-32.

21. Jagadish Kumar K, Asha N, Srinivasa Murthy D, Sujatha M, Manjunath V. Maternal anemia in various trimesters and its effect on newborn weight and maturity: an observational study. Int J Prev Med 2013;4:193-99.

22. Chapman L, Durham RF. Antepartal period: maternal newborn nursing the critical components of nursing care. Philadelphia: F.A. Davis Company; 2010.

23. Çıtıl R, Yakıştıran Barut S, Eğri M, Önder Y. Devlet hastanesine başvuran gebelerde anemi görülme sıklığı ve etkileyen faktörler [Anemia prevalence and related factors in pregnant women admitted to state hospital]. Çağdaş Tıp Dergisi 2014;4:76-83 [in Turkish].

24. Saccone G, Berghella V. Folic acid supplementation in pregnancy to prevent preterm birth: a systematic review and meta-analysis of randomized controlled trials. Eur J Obstet Gynecol Reprod Biol 2016;199:76-81.

25. Yakoob MY, Khan YP, Bhutta ZA. Maternal mineral and vitamin supplementation in pregnancy. Expert Rev Obstet Gynecol 2010;5:241-56.

26. Vanderjagt DJ, Ujah IA, Patel A, Kellywood J, Crossey MJ, Allen $\mathrm{RH}$, et al. Subclinical vitamin B12 deficiency in pregnant women attending an antenatal clinic in Nigeria. J Obstet Gynaecol 2009;29:288-95.

27. Rumbold A, Ota E, Nagata C, Shahrook S, Crowther CA. Vitamin C supplementation in pregnancy. Cochrane Database Syst Rev 2015;29:CD004072.

28. Rumbold A, Ota E, Hori H, Miyazaki C, Crowther CA. Vitamin E supplementation in pregnancy. Cochrane Database Syst Rev 2015;7:CD004069. 